\title{
SOBERANIA OU “GLOBALIZAC̣ÃO”? REFLEXÕES SOBRE UM APARENTE ANTAGONISMO
}

\author{
Diego Pautasso ${ }^{1}$ \\ Marcelo Pereira Fernandes ${ }^{2}$
}

\section{Introdução}

Durante as últimas décadas, sobretudo com a desintegração do campo soviético e a projeção do pensamento neoliberal, tornou-se lugar comum falar no fim dos Estados e/ou na erosão da soberania, ao passo que se tornou corrente justificar todas as dinâmicas sociais como consequência do que se convencionou chamar de "globalização". O presente artigo pretende problematizar o suposto antagonismo entre, de um lado, capacidade estatal e soberania e, de outro, a "globalização", aqui entendida como integração dos mercados em âmbito mundial e a consequente intensificação dos fluxos de mercadorias, capital, informação e pessoas. Há, aliás, um maniqueísmo corrente que costuma reduzir as abordagens em "globalistas" e "céticos", como é o caso de Held e McGrew (200I), que pouco contribui para entender o sistema internacional contemporâneo. Estudos sobre a "globalização", embora reconheçam a coexistência de tensões entre escalas subnacional e supranacional, acabam por destacar a redução da autonomia nacional diante da assim chamada "globalização" (Mittelman I996, 7-8). Apanhados de teorias sobre o mundo contemporâneo e a "globalização" dão conta ou de subestimar ou de negligenciar a questão estatal (Kumar I997; Ianni I996). E no âmbito das Relações Inter-

\footnotetext{
I Doutor em Ciência Política pela Universidade Federal do Rio Grande do Sul (UFRGS), atualmente é Professor de Relações Internacionais na Universidade do Vale do Rio dos Sinos (UNISINOS) e pesquisador do Núcleo Brasileiro de Estratégia e Relações Internacionais (NERINT-UFRGS) e do Centro Brasileiro de Estudos Africanos (CEBRAFRICA-UFRGS). E-mail: dgpautasso@gmail.com

2 Doutor em Economia pela Universidade Federal Fluminense (UFF) e Professor do Departamento de Economia da Universidade Federal Rural do Rio de Janeiro (UFRRJ).
} 
nacionais (RI), ou se adere a visões estado-cêntricas acríticas acerca da categoria Estado, sem atentar-se para suas cisões internas e suas transformações sistêmicas (Waltz I979), ou, no outro polo, adere-se entusiasticamente à ênfase nas forças supostamente transacionais.

É nesse sentido que se torna imperativo discutir o Estado, afinal este tem sido causa e consequência da formação do sistema internacional, o lócus de acumulação de riqueza e de poder, o principal instrumento de construção dos regimes internacionais e mesmo o aparelho político objeto e promotor dos processos internacionais. Assim, a expansão das formações estatais e seu fortalecimento enquanto capacidade burocrática coincide com a maior integração da economia em escala global, de modo que, ao invés de antagonismo, estas são dinâmicas que se fortalecem mutuamente, embora não sem contradições.

Nesse sentido, deve-se superar o suposto antagonismo entre visões estado-cêntricas e transnacionalista que acabam por imperar na área de RI, em favor de abordagens críticas que compreendam o entrelaçamento entre Estado e a internacionalização do capital, atravessados pelo processo de expansão do capitalismo na contemporaneidade. E, como tal, na linha de Losurdo (2015a, 63), isso requer uma teoria geral do conflito social que leve em conta as diversas formas que as lutas de classes e os conflitos sociais assumem: questões de gênero e/ou familiar; racial e étnica; luta de classe e entre frações de mesma classe; e - o que é sobremaneira importante nos estudos das RI - entre Estados e nações. Isso significa enfatizar que os conflitos sociais são multifacetados e multiescalares, assumem prioridades distintas em cada espaço e tempo. E é nessa linha que há contribuições distintas que podem enriquecer as abordagens críticas (Bartolovich e Lazaruz 2002)3 , em especial quando trata-se dos grupos sociais e países subalternos em escala global.

Para tanto, o trabalho está organizado da seguinte forma. Na primeira seção discutiremos a importância do Estado para formação do sistema internacional e como agente de acumulação de riqueza e poder. Na segunda seção, analisaremos alguns mitos sobre a crise do Estado e da chamada "globalização" com o objetivo de compreender melhor o vínculo inseparável entre Estado e internacionalização do capital. Na terceira seção discutiremos o papel da soberania, destacando seu caráter não absoluto dentro do sistema internacional. Na quarta seção, abordaremos algumas limitações que ainda

\footnotetext{
3 Em razão de visões estereotipadas, como destacam estes mesmo autores (Bartolovich e Lazaruz 2002) tal aproximação foi comprometida: o marxismo era visto como eurocêntrico baseado em metanarrativas totalizantes e "modernizadoras", enquanto os estudos pós-coloniais eram considerados acríticos face o imperialismo, academicista e subjetivista (abstraindo as contradições materiais e produtivas do capitalismo).
} 
permanecem nos estudos das RI que tem como base o suposto antagonismo Estado-Mercado. E, por fim, breves considerações finais.

\section{Estado e a formação do sistema internacional}

O moderno sistema internacional nasceu da dialética entre Estados e capital. Se é correto pontuar, como faz Halliday (I999, I6), que havia uma expansão gradual de fluxos pré-existentes de pessoas, religião e comércio, antes da formação dos próprios Estados nacionais; deve-se destacar também que foi a centralização do poder político na península Ibérica o fator crucial para a inicial expansão marítima mercantilista. Assim, desde a origem a formação estatal forjou a economia mundial e esta esteve, como veremos, na base do atual sistema interestatal.

Apesar da existência de inúmeras abordagens acerca da formação dos Estados modernos, das nações e dos nacionalismos (Balakrishnan 2000), o fato é que a relação entre território, fronteiras e soberania é constitutiva da formação e existência dos Estados em geral. Os Estados são organizações políticas que envolvem a construção da identidade nacional, geralmente a partir de zonas culturais precedentes, com impacto sob o "amortecimento" dos conflitos de classe (Hobsbawm I990) e a produção de coesão interna e de legitimidade na construção das fronteiras.

De acordo com Tilly (I996), coerção e capital foram forças fundamentais da formação dos Estados europeus. Os Estados são produto de complexas relações, marcado por conflitos sociais, descontinuidades históricas e uma intensa competição entre os Estados nacionais e desses com outros tipos de unidades políticas (impérios, cidades-estados, etc.). A pretensão de exercer poder de forma estável sobre populações e territórios, garantir a extração de recursos "monetizados" e fortalecer a burocracia em um ambiente de disputas e rivalidades, deu-se por meio de guerras e do uso da força. Tanto o monopólio do uso legítimo da força quanto a gênese do que se reconhece por cidadania e identidade nacional enquadram-se em um limite territorial e fronteiriço. Num assertiva mais sintética, o Estado fez a guerra e a guerra fez o Estado, de modo que coerção e capital se amalgamaram na construção dos Estados modernos, numa sofisticada engrenagem de acumulação de poder e de riqueza (Tilly i996).

De um lado, a expansão competitiva entre os Estados criou impérios coloniais e internacionalizou o capitalismo, sobretudo após o novo ciclo imperialista desencadeado após o fim do século XIX, dominando a África e a Ásia quase em sua totalidade. Da mesma forma que o colonialismo domi- 
nou a América durante mais de três séculos (entre os séculos XVI e início do XIX), a criação do espaço mundial forjou-se em compasso com a difusão de formações estatais. Com aquilo que Hobsbawm (I977) chamou de "dupla revolução” - a Revolução Industrial e a Revolução Francesa -, ocorreu a progressiva unificação do globo pelo capitalismo, incorporando, dominando e desfazendo as diversas formas de sociedades com o qual se deparava. Paralelo a isso, no topo se observava o recrudescimento da concentração da riqueza, da renda e do poder em escala global, com efeitos destrutivos sobre a democracia e as instituições, com bem destacou Piketty (20I4).

Assim, como chamou a atenção Fernandes (I999), a grande contribuição do marxismo, oriunda já do Manifesto Comunista de Marx e Engels, é a capacidade de compreender a internacionalização do capital como um processo articulado e contraditório, expresso pela difusão mundial da forma política do Estado moderno e de suas instituições, e pela integração de mercados promovida pela necessidade interna do capital expandir-se. Isto é, o moderno sistema mundial é produto da complexa dialética entre Estado e capital, refletido nas reorganizações tanto da economia capitalista quanto da geografia do poder mundial (Arrighi I996). De acordo com Fiori (2008), estão, por isso, imbricados a expansão do capital e a nacionalização do poder, não só das forças armadas e das burocracias, mas de moedas, bancos e identidades.

Se tais argumentações possuem fundamentos, é possível sobrepujar o maniqueísmo acerca do suposto antagonismo entre Estado e mercado nas Relações Internacionais e além. De um lado, as teorias de matriz realista focam em demasia na estabilidade e nos padrões de repetição do sistema, subestimando as transformações históricas e as mudanças sistêmicas. De outro, por vezes estudos de orientação liberal, na tentativa de expurgar o estado-centrismo, acabam, mesmo as abordagens críticas, por superestimar as forças supostamente transnacionais, como faz Robinson (I998), supondo como novidade todas as transformações, inclusive processos intrínsecos à formação do sistema internacional. O problema, pois, não é a necessidade óbvia de reconhecer as mudanças das características e intensidade dos processos de expansão do capitalismo na atualidade, mas tomar como antagônico aquilo que tem sido simbiótico. Aliás, desde o Manifesto se compreende o papel do Estado não como entrave à expansão do capital, mas como seu "comitê gestor", como seu lócus de poder (Marx e Engels I998).

Ou seja, não é possível invisibilizar - ou mesmo subestimar - a conexão histórica necessária entre acumulação de poder (estatal) e de riqueza (capital). Como apontou Wallerstein (200I, 4I-50), a política de acumulação de um Estado dá-se pelos seguintes atributos: I) a jurisdição territorial, que controla as fronteiras e os fluxos de bens, capitais, trabalho; 2) o direito legal, 
que define que regras governam as relações sociais; 3) a cobrança de impostos, que surge como principal fonte de renda estatal e de políticas para promoção da acumulação (subsídios, investimentos públicos, etc.); e 4) e o monopólio da força que, internamente, garante a manutenção da "ordem" e, internacionalmente, (re)produz as assimetrias de poder.

Inclusive a problemática do sistema internacional como anárquico, assimétrico e global só podem ser devidamente compreendidas dentro dessas premissas: o Estado, como concentração máxima de poder, não trabalha contra o capital, ao contrário, utiliza-se do monopólio legitimo da força como condição de existência interna e a projeta no plano internacional como reflexo da assimetria dos próprios processos de acumulação de riqueza e poder estatais. A complexidade aumenta porque o Estado é, simultaneamente, um instrumento tanto de desenvolvimento quanto de libertação das nações oprimidas. E a própria discussão sobre o lugar do Estado nas sociedades pós-capitalistas continua obstruído. Ou, como destaca Losurdo (20I5b, 54-55), o marxismo aderiu acriticamente à noção de extinção do Estado e negligenciou a necessidade de discutir as instituições e a limitação de poder - o que em grande medida contribuiu para as formas concentradas e autônomas que assumiram o poder de Estado no socialismo real, com a consequente (con)fusão entre partido e aparelho estatal (Fernandes 2000).

\section{A “crise do Estado" e a "globalização"}

A narrativa portadora da bandeira da "crise ou definhamento do Estado” está envolta num misto de imprecisões e interesses específicos. Ou seja, aprofundamento da integração dos mercados mundiais não é uma força teleológica, mas reflete conflitos políticos e territoriais entre atores específicos, estruturas hegemônicas de poder atravessadas por interesses das grandes corporações globais e dos principais Estados no sistema internacional. As teorias da "globalização" que a tratam como um novo período histórico de um mundo capitalista sem fronteiras, disponível para exploração de capital supostamente apátrida, acaba por obscurecer ou negar aspectos fundamentais quanto ao funcionamento do sistema internacional (Halliday 2002; Petras e Veltmeyer 2007; Ruccio 2003). Na realidade, a ideia de "globalização" suprime uma série de questões relacionadas ao desenvolvimento histórico das relações de exploração dentro dos Estados e no âmbito sistêmico - o que inclui as assimetrias globais e o papel do imperialismo como referência teórica e histórica (Sakellaropoulos 2009).

Primeiro, em âmbito interno, os Estados dependem de capacidades 
múltiplas, envolvendo a arrecadação e gestão de recursos a partir de instituições e um sistema de regras, além dos meios de imposição da ordem e defesa nacional - construídos politicamente pelo entrelaçamento entre coerção, consenso e cooptação. Com efeito, como define Tilly (2013), esta capacidade estatal determina como o Estado penetra na sociedade e altera a distribuição de recursos, atividades e conexões interpessoais - ou seja, é um conceito polissêmico, multidimensional e transdisciplinar central para definir o papel do Estado na promoção do desenvolvimento.

Apesar das narrativas dominantes, deve-se reconhecer que não houve uma retração dos Estados e de suas capacidades, seja medido pela proporção do emprego público 4 , seja pela arrecadação governamental (impostos). Nos países membros da OCDE, a carga tributária subiu de 24,8\% em I965 para $30,1 \%$ em I980, 32,2\% em I990, 34,2\% em 2000 e 34,I\% em 2013. Mesmo os promotores do discurso liberal como EUA, Grã-Bretanha e Alemanha tinham taxas de $25,5 \%, 33,5 \%$ e $36,4 \%$ em ig 80 e culminam com $25,4 \%, 32,9 \%$ e $36,7 \%$, respectivamente, em 2013 , mantendo-se estável5. A riqueza de dados de Piketty (2014, I36-137) é reforçada pelo fato de que os valores totais dos ativos públicos da França e Reino Unido se expandiram de 50\% nos séculos XVIII e XIX para cerca de Io०\% da renda nacional nos séculos XX e XXI. Quando se observa a importância que o conjunto de impostos e arrecadação passou a exercer na renda nacional de países como Suécia, França, Reino Unido e EUA entre I870 e 20ıo, não resta dúvida a evolução do papel do poder público nas sociedades desenvolvidas (Piketty 20I4, 463), como bem ilustram os dados da $\mathrm{OCDE}^{6}$. Assim, como destaca Losurdo (20I5a, I3), a constituição do Estado de Bem Estar Social na Europa (e os ataques que estes vêm sofrendo na atualidade) está relacionado com a mobilização política e social das classes subalternas. A combinação de mobilização das lutas domésticas pela apropriação da riqueza e a influência do bloco socialista pesaram decisivamente na ampliação das atribuições do Estado em serviços públicos e infraestrutura para amplos segmentos da população. Por isso, o colapso do campo soviético e a ascensão do neoliberalismo potencializou o desmonte das políticas públicas universalistas.

4 Ao observar o desempenho dos países desenvolvidos em relação ao emprego público diante do total de ocupados, nota-se um crescimento substantivo entre as décadas de ig6o e 80 e, a partir da supremacia do discurso liberal houve, no máximo, uma estabilidade. Dados disponível em estudo do IPEA: http://www.ipea.gov.br/portal/images/stories/PDFs/TDs/td_I578.pdf. 5 A série estatística da OCDE permite observar o comportamento da carga tributária no conjunto dos países. Disponível em: http://stats.oecd.org/Index.aspx?DataSetCode=REV.

6 Ver os dados detalhados oferecidos pelo relatório da OCDE disponível em: http://www.oecd. org/els/soc/OECD2OI4-Social-Expenditure-Update-Nov2or4-8pages.pdf. 
Segundo, em âmbito internacional, o lugar dos Estados no mundo deve levar em conta o caráter anárquico, competitivo e assimétrico do sistema internacional. Primeiro, cabe recordar que o imperialismo foi uma das facetas da política expansionista da liberal Inglaterra do século XIX (Losurdo 20I5b, 258) e voltou a imperar com o advento do neoliberalismo se utilizando da sofisticada estrutura dos organismos internacionais como FMI, BIRD, Banco Central Europeu e OMC, cujo objetivo foi - entre outras coisas - servir aos interesses dos países centrais (Chang 2004; 2008) e abrir novas fronteiras de acumulação para as grandes potências?. Pode-se sublinhar também que o "imperialismo de livre-comércio" não está dissociado do "imperialismo dos direitos humanos" e das motivações de intervir em Estados periféricos. O atual "intervencionismo democrático" e humanitário reedita o imperialismo colonial, com retóricas semelhantes de guerra pela paz, pela liberdade e pela civilização ocidental (Losurdo 2015b, 65-87). Os novos meios informacionais (Internet War e Psywar) e militares (Revolution in Military Affairs) se entrelaçam convertendo o espetáculo como técnica de guerra e, por extensão, potencializando os objetivos estratégicos das potências ocidentais (Losurdo 20I6, I09-I60).

Reconhecer os elementos de continuidade não impede de reconhecer que o sistema capitalista vem passando por profundas transformações desde sua origem, cujas mudanças tecnológicas aceleram a integração e os fluxos de capitais e de mercadorias, provocando reorganização nas estruturas hegemônicas de poder e em suas hierarquias no mundo. Para tanto, como já destacamos, leituras apressadas têm subestimado o papel do Estado na contemporaneidade, assim como superestimado as novidades da internacionalização do capital.

Nesse sentido, Batista Jr. (I998) confrontou - com riqueza de dados quantitativos - o que chamou de os cinco mitos da "globalização". Primeiro, não inaugura uma etapa na história econômica mundial, pois, em diversos aspectos, o grau de integração internacional alcançado entre i870 e i9ı4 é comparável, ou até superior, ao observado na economia "globalizada" do final do século XX. Segundo, não houve a dissolução das fronteiras nacionais em favor de um mercado mundial, apesar do progresso técnico e das inovações, devido à preponderância da geração de riqueza em âmbito doméstico e à concentração dos fluxos de riqueza em âmbito global nos países desenvolvidos. Terceiro, não há um declínio inexorável dos Estados nacionais em razão das políticas neoliberais, uma vez que a dimensão do Estado na grande maioria

7 É ilustrativo o caso da criação do OMC, com maiores compromissos e obrigações para os seus participantes em temas de investimento (TRIMS), de serviços (GATS) e de propriedade intelectual (TRIPS). 
das economias persiste, medido por indicadores agregados, como a relação entre a despesa e a receita públicas e o PIB. Quarto, não há domínio previsto das tais empresas "transnacionais", já que se trata de empresas com lealdades nacionais, mantendo o grosso dos seus ativos, vendas e empregos e, sobretudo, capacidade decisória na sua base nacional. Quinto e último, não procede o argumento de que as transações financeiras globais liquidaram a autonomia das políticas nacionais, na medida em que, mesmo com a acentuada expansão das operações financeiras internacionais, as aplicações domésticas ainda são largamente predominantes e dependentes de seus bancos centrais. Ou melhor, como destaca Ghemawat (2009), com um conjunto substantivo de dados ${ }^{8}$, o mundo global é menos plano do que nos fazem crer os discursos dominantes.

Assim, não por coincidência, o discurso que associa crise dos Estados e "globalização" se fortaleceu justamente no contexto em que os EUA aproveitavam o fim do bloco soviético para projetar poder em escala global, buscando criar e consolidar um mundo unipolar e a agenda de liberalização dos mercados pós-socialistas e/ou desenvolvimentistas. Paradoxalmente, o discurso dominante passou a convergir com aqueles esquerdistas - inclusive de tendência marxista - críticos ao poder e à importância dos Estados na ordem mundial. No último caso, o argumento somava-se à ideia de permanente crise terminal do capitalismo e do colapso dos EUA. Além de dificultar a compreensão da dinâmica de poder no mundo, tais concepções emperram a formulação de qualquer projeto nacional alternativo e por vezes contribuindo para fragilizar experiências keynesianas, desenvolvimentistas e socialistas. Indiferente à relevância do debate sobre o declínio dos EUA (Wallerstein 2004; Fiori 2008) e a emergência de um mundo multipolar, o certo é que não se pode subestimar a liderança norte-americana9.

Em suma, compreender a relação íntima e simbiótica entre Estado e a internacionalização do capital na formação e nas transformações do sistema internacional é central para abarcar a complexidade desses fenômenos. Assim sendo, não se pode esquecer o caráter histórico de certas dinâmicas globais ${ }^{\mathrm{IO}}$

8 Ver dados disponíveis no site pessoal do autor indiano: http://www.ghemawat.com/.

9 Desde os anos I950, com a revolução chinesa, os revezes na península coreana e a liderança inicial russa na corrida espacial; depois nos anos I970, com o fim do padrão dólar-ouro, a derrota no Vietnã e os choques petrolíferos; nos anos i980, com o "cinturão da ferrugem" em Detroit e os déficits gêmeos crescentes; e, por fim, no século XXI com as agressões de II/9, as dificuldades nas intervenções no Afeganistão e Iraque e a crise do subprime em 2008. Ironicamente, apesar dos desafios (e até declínio relativo), os EUA venceram a ordem bipolar, tornaram-se líderes na 3 ffi Revolução Industrial, foram um dos primeiros a sair da crise e, agora, dão um grande passo na superação de sua vulnerabilidade energética a partir das reservas de xisto. ıo Halliday (I999, II8), chama a atenção de que muitos processos que caracterizam o transna- 
(migrações, comércio, turismo, refugiados, ativistas políticos), tampouco subestimar a internacionalização do capital - sobretudo sua atual financeirização - na motivação profunda de reações nacionais, promoção de identidades e recrudescimento de desigualdades.

\section{Estado e soberania no espaço mundial}

O Estado e a soberania estão intimamente ligados e remetem ao sujeito da política, como autoridade constituída com monopólio legítimo da força sob um determinado território e população e com reconhecimento diplomático internacional. Menos que a evolução do debate conceitual - origens, definições, formas e teorias -, interessa aqui questionar a suposição de que a crise do Estado teria levado à erosão da soberania estatal e quais suas implicações.

Quanto à suposição da relação entre definhamento do Estado e por extensão da soberania, deve-se dizer que tais conclusões estão equivocadas ao tomar como premissa o caráter absoluto e monista da soberania. O equívoco está, pois, em considerar a soberania como algo absoluto, pois os Estados se formaram num sistema global, assimétrico e anárquico; quer dizer, imerso em fluxos globais de pessoas, informações, conhecimentos e mercadorias e submetido à distribuição desigual de riqueza e poder - e por estes fatores são condicionados. Nesse sentido, é evidente que há Estados com maior ou menor soberania dentro do sistema. Ou como destaca Halliday (1999, 97), ter o monopólio do poder e a legitimidade dentro de um território, bem como reconhecimento diplomático e jurídico internacionais, não implica desconhecer que há limites nacionais e globais à capacidade de controle do Estado. Assim, não faz sentido a própria separação rígida entre externo e interno, pois implica em negligenciar as clivagens e assimetrias que perpassam essa dialética de formação do sistema internacional. Se, por um lado, o princípio da soberania reside na capacidade de garantir autonomia decisória e independência ao país, por outro, este não é absoluto, pois a interdependência é da natureza formativa do sistema internacional.

Por isso, o sistema vestefaliano consagra formalmente soberania internamente e a igualdade internacionalmente, embora nem nenhum dos casos deva ser absolutizada, dada as diferenças de capacidade material e política. Como destaca Kissinger (2015, 34-35), tal sistema tomava a multiplicidade de forças como seu ponto de partida na busca comum por ordem, mediado por fóruns para a resolução de conflitos com seus respectivos arranjos legais. Se-

cionalismo contemporâneo estavam presentes décadas, e mesmo séculos atrás, como a Reforma, a Revolução Industrial, a disseminação do sufrágio universal e as migrações. 
gundo o mesmo autor, o sistema vestfaliano vem enfrentando desafios ligados I) ao conceito de soberania compartilhada da integração europeia; 2) ao jihadismo que toma a religião e não o Estado como referência; 3) e ao excepcionalismo dos EUA que relativiza noções de soberania (Kissinger 2015, I5), seja em intervenções humanitárias, em "revoluções coloridas" ou em agressões por meio de drones sem nenhuma atenção ao direito internacional.

Quanto às implicações decorrentes do discurso relativo à erosão da soberania cabe lembrar que há linha tênue que a separa do crescente protagonismo das organizações internacionais e seus sistemas de governança. Deve-se atentar, porém, que por detrás de diferentes concepções e referências normativas, ligados aos direitos humanos e à democracia, há também interesses de potências em ampliar o escopo das intervenções (Bartelson 2006). O fortalecimento do sistema de governança e do direito internacional no último meio século não implica num arranjo supraestatal, mas na adoção de países a tratados, cuja aplicação dessas regras depende da mobilização e das capacidades dos países signatários. O contrário da soberania não é, como pode parecer, a "vontade geral" da comunidade internacional, mas as regras e sua imposição por países (potências) com capacidade de coagir e impor as normas num sistema anárquico.

Ao invés dessa "vontade geral" comunitária, como destacou Losurdo (I998, 87-88), a construção do universal tem cabido às potências e, por extensão, confunde-se com etnocentrismo e com imperialismo. Não raro as grandes potências mobilizam discursos voltados a assegurar a "paz" e expandir a "civilização", o "mercado livre" e o "direito", enquanto projetam seus poderes em escala global, desde o colonialismo do século XVI às intervenções estrangeiras contemporâneas ${ }^{\text {II }}$. Muitos esquecem que há ambiciosos interesses buscando eliminar as amarras estatais (soberania) para legitimar e legalizar novas guerras. Muitas vezes o argumento em favor da segurança humana é posto em oposição e para desfazer a segurança dos Estados; só que o excepcionalismo e o imperialismo representam também a mais forte ameaça à segurança dos Estados (periféricos) e dos indivíduos (Walker 2006). Não se trata de relativismo, mas de problematizar a construção e aplicação dos ordenamentos legais e dos códigos culturais num sistema profundamente heterogêneo e assimétrico.

É por estas razões que a soberania assumiu sentidos políticos distintos, entre sua formulação vestfaliana e a atualidade. Não por acaso, para as

II No Pós Guerra Fria, tem sido recorrente as intervenções, violações institucionais e crimes de guerra, como nos casos da invasão do Panamá, da Iugoslávia, do Iraque pelos EUA e OTAN nos anos I990, ou no Afeganistão, Iraque novamente e Líbia e Síria no século XXI - para ficar nas mais importantes. 
potências, o conceito de soberania deixou de estar no centro das formulações político-diplomáticas e tampouco acadêmicas. Isso decorre, em primeiro lugar, do fato de a soberania estar (ou parece) equacionada no âmbito territorial pela superioridade militar historicamente consolidada. Segundo, porque tais potências possuem capacidade de resistir a decisões contrárias a seus interesses domésticos, mesmo que decorrentes de regimes e organismos internacionais. Pode-se ilustrar com as violações cometidas pelos EUA com a Guerra ao Terror bem documentada por Scahill (20I4) ou pela prática de gigantescos subsídios agrícolas em contraposição ao que as próprias potências (e a OMC) defendem para o setor. Terceiro, estas potências são as grandes construtoras dos ordenamentos legais, de modo que estes convergem com seus interesses mais gerais.

Em suma, as necessidades destas potências viabilizam-se justamente pela extensão de seus interesses em escala global por meio da força, das corporações e/ou de seus regimes internacionais - o que pressupõe a flexibilização, justamente, dos Estados e de sua soberania. Não se trata, como é óbvio, de desacreditar as organizações interestatais e os regimes internacionais e seus mecanismos de governança. Mas sim alertar para o fato de que o alargamento das atribuições de tais organizações, sob domínio das grandes potências, acompanhado da consequente fragilização dos Estados nacionais, têm recrudescido a assimetria do sistema internacional. Em outras palavras, ao reconhecer a relação entre soberania e as capacidades estatais de cada país, podemos compreender as motivações e as contradições que envolvem as relações entre Estados nacionais e as organizações e regimes internacionais.

Além das motivações ligadas à narrativa de definhamento do Estado e da soberania no atual contexto (pós-Guerra Fria) não é difícil de reconhecer que há outras limitações empíricas e históricas. Aliás, como concluir que há um enfraquecimento da soberania quando foi justamente no último quartel do século XX que a maior parte do mundo passou a ser formada por países independentes? A ONU foi fundada em 1944 com 5I membros, pois a maior parte da África e Ásia era colônia, e hoje conta com I96 países. Antes disso, por óbvio, no século XIX os países da América estavam iniciando sua trajetória de independência das metrópoles europeias. Cabe aos entusiastas da "globalização" (como novidade) definir qual teria sido contexto de máxima afirmação do Estado e da soberania - o que seria difícil de localizar antes dos anos I990. Resta a pergunta inconveniente: quando a soberania e os Estados tiveram sua máxima expressão para depois enfrentar o processo de definhamento? Em síntese, as abordagens globalistas realizam a falácia do espantalho: constroem uma versão distorcida, supondo soberania absoluta e grande poder estatal, para facilitar o argumento que pretendem refutar. 


\section{Para além do antagonismo Estado-Mercado}

Apesar dos avanços teóricos da área de Relações Internacionais, ainda é imperativo discutir Estado, soberania e "globalização". O diálogo com outras áreas das Humanidades contribui para transcender limitações conceituais e empíricas que ainda imperam nos estudos internacionais. A primeira das limitações é a persistente manutenção do conceito de Estado como "bola de bilhar” (Huntington I997, 35) que, além de a-históricas, oculta cisões e tensões existentes entre Estado/sociedade, Estado/governo e Estado/nação. Subestima-se que a complexidade do Estado reside na especificidade do político mediador e regulador de um conjunto de interações numa totalidade econômica global, donde os níveis doméstico e internacional se entrecruzam (Halliday I999, 94-95; 104).

A segunda limitação é a não compreensão de que se, por um lado, as tecnologias aprofundam a integração do espaço mundial e os fluxos transfronteiriços de capitais, por outro, estes meios técnicos fortalecem as capacidades estatais. Em âmbito doméstico, o governo eletrônico amplia drasticamente a capacidade de atuação do setor público em atividades diversas envolvendo tributação, fiscalização, planejamento, prestação de serviços, etc. Em âmbito internacional, os meios da atual revolução tecnológica também potencializaram as assimetrias de poder interestatais, através do comando do espaço (satélites) e da inteligência artificial que permitem a automação de diversas operações, como munições guiadas, drones, ciberguerra, etc. Como destaca Duarte (20I2), a tecnologia não decide nem conduz guerras, mas é crucial para definir as condições de enfrentamento.

A terceira limitação é desconsiderar o entrelaçamento dos conceitos de Estado, soberania e "globalização". Deve-se, como destaca Osiander (200I), superar a premissa equivocada de que a Paz de Vestfália teria sido marco no estabelecimento de uma suposta soberania absoluta ou integral. Se a soberania se refere à capacidade de controlar as atividades dentro de suas fronteiras e obter o reconhecimento dos demais Estados, esta é assimétrica e historicamente condicionada. E depende, por óbvio, das diferentes capacidades estatais e níveis de desenvolvimento dos países, de seus poderes político, militar e econômico, assim como de sua inserção internacional, que influenciam a vulnerabilidade e a autonomia decisória de um Estado.

A quarta limitação localiza-se nos autores que defendem normativamente sociedades pós-estatais como imperativo para superar aquilo que não decorre do sistema vestfaliano. É o caso de teóricos intitulados críticos que (Linklater I998; Walker I993) problematizam conceitos ligados à cons- 
trução nacional-estatal, tais como nacionalidade, cidadania, territorialidade e soberania e suas consequentes oposições, como soberania-anarquia, segurança-ameaça, identidade-diferença. O problema é que tais cisões e tensões não decorrem do sistema vestfaliano, mas de processos de emancipação-desemancipação que perpassam os complexos processos de desenvolvimento e construção do sistema internacional. O que também não é suficientemente explorado é como construir os processos emancipatórios (políticas públicas e garantias legais) à margem de instituições, da organização política e dos processos democráticos. Como bem destaca Goodhart (200I), não se constrói a democracia no contexto da "globalização" simplesmente desfazendo a realidade conturbada dos Estados soberanos, tampouco esperando por "governo mundial".

A quinta limitação são os recorrentes argumentos a favor da erosão dos Estados e de sua soberania em prol dos processos de liberalização. Frequentemente tais exemplos subestimam o entrelaçamento entre o Estado e a internacionalização do capital. Para tanto, cabe ilustrar com os casos dos processos de integração regionais e de outros atores não estatais. No primeiro caso, o exemplo europeu é frequentemente destacado, esquecendo o papel dos Estados na dinâmica integracionista, a assimetria interestatal no interior do bloco e os limites da integração justamente pelo não compartilhamento de elementos cruciais da soberania estatal (forças armadas). Ainda assim, um eventual sucesso em erigir um novo arranjo supranacional em nível europeu estaria redundando em um novo Estado europeu com as mesmas prerrogativas, porém num escopo territorial ampliado! Nos outros casos, os atores não estatais como as organizações internacionais, as organizações não governamentais e as grandes corporações não surgem, se financiam e atuam à margem do sistema interestatal. Ou seja, sem compreender as hierarquias de poder entre e intra Estados não é possível entender o peso político assimétrico em órgãos como Conselho de Segurança da ONU, FMI e OMC; a participação, adesão e cumprimento efetivos de acordos internacionais; a promoção e imposição de regras e práticas nos diversos âmbitos do sistema internacional, etc. Vale lembrar o caso das empresas multinacionais que, como destaca Chang $(2008,97)$, são no fundo empresas nacionais de atuação mundial, no qual a gestão, a inovação e o acúmulo de capital estão em estreita conexão com os interesses dos seus Estados de origem.

Por fim, pode-se concluir, curvando a vara para o polo oposto (para trazê-la ao ponto mais adequado): o século XXI será aquele em que a temática da construção estatal e da soberania estará no centro da política, pois o desafio do desenvolvimento e da construção institucional democrática (mesmo quando em processos integrativos e/ou em organizações internacionais 
e seus regimes) está posto para a maioria esmagadora dos países do sistema internacional, notadamente aqueles da África, América Latina e Ásia. Por vezes um certo etnocentrismo esquece que os desafios postos nessas regiões são ainda por conquistas anteriores a qualquer argumento pós-vestfaliano: ao contrário, a construção de uma infraestrutura básica de energia, transporte e comunicação; o estabelecimento mínimo de padrões de consumo; a prestação de serviços públicos de saúde, educação e segurança; e a organização do aparelho de administração pública. Isto é, do ponto de vista de uma abordagem marxista, desconsiderar a importância do Estado (e da soberania) na internacionalização do capital é desconsiderar elementos chave da teoria geral dos conflitos sociais. Primeiro, porque o Estado continua a ser o "comitê gestor da burguesia”, o epicentro político dos processos de acumulação e o instrumento de competição das respectivas frações da burguesia. Segundo, o Estado se transforma, para as nações periféricas, num elemento importante para a autonomia e a independência nacionais. Por fim, deve-se considerar que as lutas sociais estão voltadas à emancipação e estas perpassam políticas púbicas, ganhos materiais e reconhecimento - e naturalmente dependem do orçamento e das instituições públicas. Reiterando a questão levantada por Losurdo (2015a), as lutas de classes não se resumem à simplificadora versão de conflito operário e burguês em chão de fábrica, mas as diversas formas que assumem os conflitos sociais e os processos de emancipação/desemancipação, como lutas interestatais, de raça, de gênero e de segmentos sociais distinto ${ }^{12}$.

\section{Considerações finais}

Reconhecer, como fazem os estudiosos da "globalização", que existem estruturas, processos e fenômenos emergentes contemporaneamente é importante - isso se refere, aliás, inerentemente aos processos sociais e históricos. A relação entre territorialidade e fluxos ou entre escalas geográficas (local-global) configuram-se motivadas por transformações tecnológicas e rearranjos econômicos e políticos. A questão de fundo não são essas constatações (por vezes truísmos), mas a compreensão das transformações e da maneira pelo qual os Estados ganham não só nova importância, mas capacidades ampliadas. É errôneo, pois, o argumento (de matriz liberal) que ten-

I2 Embora seja recorrente tanto as leituras dogmáticas por parte de certa esquerda quanto as iniciativas conservadoras de deslegitimar abordagens críticas marxistas, o fato é que desde sua origem seus principais formuladores atentaram-se para uma versão ampliada das lutas de classes. Basta ver as diversas publicações de Lênin sobre a questão de gênero quando esse tema sequer estava na agenda política nem dos Estados e nem das forças políticas dominantes. Ver Lênin (1956). 
de a antepor Estado e mercado, soberania e "globalização", desconsiderando a trajetória formativa do sistema internacional, incluindo guerras, moedas, acordos interestatais, etc. Ademais, contraria evidências empíricas, tais como a notória integração global dos países mais desenvolvidos (e soberanos), em contraposição a dos Estados falidos à margem da "globalização". Em outras palavras, os mercados organizados dos países desenvolvidos impõem capacidade burocrática e institucional, da mesma forma que o mercado global não decorre apenas de escolhas das grandes corporações.

É interessante observar como abordagens focadas nos discursos "globalistas" e "pós-vestfaliano" desconsideram demandas básicas da grande maioria dos países, periféricos e emergentes, representantes de cerca de $85 \%$ dos países e da população mundiais à margem do restrito círculo dos membros ricos da OCDE. A necessidade de compreender as estruturas hegemônicas de poder e sua ligação com a produção de riqueza em escala global (capital), situando as contradições e disputas políticas intraestatais, bem como as assimetrias e hierarquias interestatais, requerem uma compreensão da dialética da "globalização" e uma perspectiva que escape ao etnocentrismo reinante nas RI.

O entrelaçamento entre as dinâmicas mundial e interestatal são mais complexas; e os próprios eventos internacionais ocorridos no Pós-Guerra Fria contradisseram discursos "globalistas": a formação de novos Estados (na ex-Iugoslávia, ex-URSS, ex-Tchecoslováquia, Eritreia, Sudão do Sul), o recrudescimento de movimentos separatistas reivindicadores de Estados territoriais (Chechênia, Daguestão, Inguchétia, na Rússia; Xinjiang e Tibet, na China; no Cáucaso; no Curdistão; no País Basco; na Escócia); as próprias guerras civis e a consequente disputa pelo aparelho estatal (particularmente na África, como RD do Congo, Angola, Ruanda); a crescente disputa por recursos naturais (petróleo, água, diamantes, gás natural) como elemento central da segurança nacional; o recrudescimento do protecionismo comercial como expressão da competição interestatal; a formação de novas coalizões políticas interestatais (G20, IBAS, BRICS); o ativismo das diplomacias em instituições internacionais (ONU, OMC, FMI); o conflitos de interesses nacionais no âmbito dos processos de integração (como bem ilustra o caso grego); a intensificação das operações subterrâneas e intervenções militares conduzido pelas potências (golpe na Venezuela, "revoluções coloridas", desestabilização da Síria); as novas demandas por ações nacionais diante das ameaças transfronteiriças (SARS, terrorismo, tráfico de drogas, armas e contrabando, etc.); entre outros.

Em suma, as abordagens maniqueístas não são capazes de dar conta da complexa interação entre os Estados (suas soberanias) e as dinâmicas globais. Com efeito, as lutas sociais tendem a ficar obstruídas pela incom- 
preensão da importância dos Estados nas diversas faces que assumem os processos de emancipação/desemancipação que atravessam o sistema internacional.

\section{REFERÊNCIAS}

Arrighi, Giovanni. I996. O longo século XX: dinheiro, poder e as origens de nosso tempo. São Paulo: UNESP/Contraponto.

Balakrishnan, Gopal. 2000. Um mapa da questão nacional. Rio de Janeiro: Contraponto.

Baldwin, David. I993. "Neoliberalism, Neorealism, and World Politics". In Neorealism and Neoliberalism: the Contemporary Debate, 3-II. New York: Columbia University Press.

Bartelson, Jens. 2006. "The concept of sovereignty revisited". The European Journal of International Law I7 (2): 463-74.

Bartolovich, Crystal, and Neil Lazarus. 2002. Marxism, Modernity, and Postcolonial studies. New York: Cambridge University Press.

Bobbio, Norberto. I986. O futuro da democracia. São Paulo: Paz e Terra.

Castro, Thales. 2012. Teoria das Relações Internacionais. Brasilia: FUNAG.

Chang Ha-joon. 2008. Maus samaritanos. São Paulo: Campus.

2004. Chutando a escada. São Paulo: UNESP.

Damin, Cláudio. 20I3. "Poder de Guerra nos Estados Unidos: a Cláusula de Guerra, o precedente coreano de 1950 e a autonomia do Comandante-em-Chefe". PhD thesis, Federal University of Rio Grande do Sul (UFRGS).

Dougherty, James, and Robert Pfaltzgraff. 2003. Relações Internacionais: teorias em confronto. Lisboa: Gradiva.

Doyle, Michael. I983. "Kant, liberal legacies and foreign affairs". Philosophy and public affairs I2 (3-4): 205-35; 325-53.

Duarte, Érico. 2012. Conduta da Guerra na Era Digital e suas implicações para o Brasil. Paper for discussion i760. Brasília: IPEA.

Dunne, Tim. 2008. "Liberalism”. In The globalization of world politics, IIoI22. New York: Oxford University Press.

Esping-Andersen, Gøsta. I990. The Three Worlds of Welfare Capitalism. Princeton: Princeton University Press.

Fernandes, Luís. I999. “O Manifesto Comunista e o 'elo perdido’ do sistema inter- 
nacional". Contexto Internacional 20 (I): 219-234.

2000. O enigma do Socialismo Real. Rio de Janeiro: Mauad.

Fiori, José, Carlos Medeiros, and Franklin Serrano. 2008. O mito do colapso do poder americano. Rio de Janeiro: Record.

Fonseca, Carlos. 2007. "Deus está do nosso lado: excepcionalismo e religião nos EUA". Contexto Internacional 29 (I): I49-I85.

Galbraith, John. 2004. A economia das fraudes inocentes. São Paulo: Cia das Letras.

Ghemawat, Pankaj. 2007. "Why the World Isn't Flat". Foreign Policy (I59): 5460.

Gill, Stephen. 2008. Power and resistance in the new world order. New York: Palgrave Macmillan.

Gill, Stephen. 2007. Gramsci, materialismo histórico e relações internacionais. Rio de Janeiro: UFRJ.

Goodhart, Michael. 200I. "Sovereignty: reckoning what is real". Polity 34 (2): 24I-57.

Halliday, Fred. I999. Repensando as relações internacionais. Porto Alegre: UFRGS.

Hayek, Friedrich. 20I0. O caminho da servidão. São Paulo: Instituto Ludwig von Mises Brasil.

Held, David, and Anthony McGrew. 200I. Prós e contras da globalização. Rio de Janeiro: Zahar.

Hobsbawm, Eric. I970. Nações e nacionalismo desde 1780. Rio de Janeiro: Paz e Terra. . I977. A era das revoluções. Rio de Janeiro: Paz e Terra.

Huntington, Samuel. I997. O choque de civilizações e a recomposição da ordem mundial. São Paulo: Objetiva.

Ianni, Octavio. I996. Teorias da globalização. Rio de Janeiro: Civilização Brasileira.

Kissinger, Henry. 2015. Ordem Mundial. São Paulo: Objetiva.

Keohane, Robert, and Joseph Nye. I971. Transnational relations and world politics. Cambridge: Harvard University Press. I977. Power and interdependence: world politics in transition. Boston: Little, Brown and Company.

Kumar, Krishan. I997. Da sociedade pós-industrial à pós-moderna. Rio de Janeiro: Zahar. 
Lenin, Vladimir. I956. O socialismo e a emancipação da mulher. Rio de Janeiro: Vitória, 1956.

Lima, Venício. 20ıо. Liberdade de expressão vs. liberdade de imprensa - Direito à comunicação e democracia. São Paulo: Editora Publisher Brasil.

Linklater, Andrew. I998. The transformation of political community. Columbia: South Carolina Press.

Locke, John. 2004. Segundo tratado sobre o governo. São Paulo: Martin Claret. Losurdo, Domenico. I998. Hegel, Marx e a Tradição Liberal. São Paulo: UNESP, 1998. 2004. Democracia ou bonapartismo. Rio de Janeiro: UFRJ/UNESP. . 2006a. Contra-história do Liberalismo. Aparecida-SP: Ideias \& Letras. . 2006b. Liberalismo: entre civilização e barbárie. São Paulo: Anita Garibaldi.

. 2010. Linguagem do Império. São Paulo: Contraponto.

. 20I2. A não violência: uma história fora do mito. Rio de Janeiro: Revan. . 2015a. A luta de classes. São Paulo: Boitempo.

. 20I5b. Marx e o balanço histórico do século XXI. São Paulo: Anita Garibaldi.

. 20I6. A esquerda ausente. São Paulo: Anita Garibaldi.

Marx, Karl, and Friedrich Engels. I998. Manifesto Comunista. São Paulo: Boitempo.

. 200I. Manifesto do Partido Comunista. São Paulo: Anita Garibaldi.

Mazzetti, Mark. 20I3. The Way of the Knife: the CIA, a Secret Army, and a War at the Ends of the Earth. New York: Penguin Books.

Mearshimer, John. 2000. "A realist reply". In Theories of war and peace. Cambridge: MIT Press.

Medeiros, Marcelo. 20II. Clássicos das Relações Internacionais. São Paulo: Hucitec.

Mittelman, James. “The dynamics of Globalization”. In Globalization: critical reflections, I-I9. Boulder: Lynne Rienner.

Moura, Gerson. I991. Estados Unidos e América Latina. Rio de Janeiro: Contexto.

Nascimento, Márcio. 20I0. A privatização do emprego da Força por Atores Não Estatais no âmbito multilateral. Brasília: FUNAG.

Nogueira, João, and Nizar Messari. 2005. Teoria das Relações Internacionais. Rio de Janeiro: Elsevier. 
Osiander, Andreas. 200I. "Sovereignty, International Relations, and the Westphalian myth". International Organization 55 (2): 25I-287.

Pautasso, Diego. 20II. "O fortalecimento das relações Sul-Sul: estratégia e realidade para os países emergentes”. Conjuntura Austral 2: 48-62.

Pecequilo, Cristina. 2004. Introdução às Relações Internacionais. Petrópolis: Vozes.

Petras, James, and Henry Veltmeyer. 2007. “Globalisation or Imperialism?". Cambridge Review of International Affairs I4 (I).

Piketty, Thomas. 20I4. O capital no século XXI. Rio de Janeiro: Intrínseca.

Richmond, Oliver. 20I0. "Para além da paz liberal?". Contexto Internacional 32 (2): 297-332.

Robinson, William. I998. "Beyond Nation-State Paradigms: Globalization, Sociology, and the Challenge of Transnational Studies". Sociological Forum I3 (4): 56I-59I.

. 2007. "Theories of Globalization". In Companion to Globalization. Oxford: Blackwell.

Ruccio, David. 2003. "Globalization and imperialism”. Rethinking Marxism I5 (I): $75-94$.

Sakellaropoulos, Spyros. 2009. "The Issue of Globalization through the Theory of Imperialism and the Periodization of Modes of Production". Critical Sociology 35 (I): 57-78.

Sarfati, Gilberto. 2005. Teoria das Relações Internacionais. Rio de Janeiro: Elsevier.

Scahill, Jeremy. 20I4. Guerras Sujas. São Paulo: Companhia das Letras.

Singer, Peter. 200I. "Corporate Warriors: the rise of the privatized military industry and its ramification for international security". International Security 26 (3): $186-220$.

Smith, Rodney. 2006. Money, Power, a Elections: How Campaign Finance Reform Subverts American Democracy. Baton Rouge: Louisiana State University Press.

Tilly, Charles. I996. Coerção, Capital e Estados Europeus. São Paulo. EDUSO. 2013. Democracia. Rio de Janeiro: Vozes.

Vigevani, Tullo, Aline R. A. Martins, and Priscila Rodrigues. 20II. "A contribuição marxista para o estudo das relações internacionais". Lua Nova (83): III-I43.

Zakaria, Fareed. I992. "Realism and domestic politics". International Security I7 (I): $177-98$. 
i ek, Slavoj. 20Iı. "O casamento entre democracia e capitalismo acabou". Carta Maior. October II. http://www.cartamaior.com.br/?/Editoria/Internacional/Zizek-o-casamento-entre-democracia-e-capitalismo-acabou/6/17832.

Wallerstein, Immanuel. 2004. O declínio do poder Americano. Rio de Janeiro: Contraponto.

Waltz, Kenneth. I979. Theory of international politics. Reading: Addison-Wesley.

Walker, Rob. 2006. "Lines of Insecurity: International, Imperial, Exceptional". Security Dialogue 37 (I): 65-82.

\section{RESUMO}

$\mathrm{O}$ artigo pretende problematizar o suposto antagonismo entre, de um lado, capacidade estatal e soberania e, de outro, a integração dos mercados em âmbito mundial. O maniqueísmo corrente que costuma reduzir as abordagens em "globalistas" e "céticos" não contribui para entender o sistema internacional contemporâneo. É necessário superar o suposto antagonismo entre visões estado-cêntricas e transnacionalista, em favor de abordagens críticas que compreendam o entrelaçamento entre Estado e a internacionalização do capital, atravessados pelo processo de expansão do capitalismo na contemporaneidade.

\section{PALAVRAS-CHAVE}

Globalização; Estado; Capital; Sistema Internacional.

Recebido em 3 de abril de 2017. Aprovado em 13 de julho de 2017. 